\title{
Swinging Consciousness or Self-Organizing Chaos as a
}

\section{Resonant System*}

\author{
Menshikova Elena Rudolfovna \\ New Institute for Cultural Research, Moscow, Russia
}

\begin{abstract}
Consciousness is the gene of resistance that drives evolution by the evolutionary method—empathic Qualia, the subjective perturbation of "natural selection", and the choice of which is not limited but stress-resistant to mistakes. Looking into the mirror of ourselves, we bring evolution itself to the mirror, which, without blinking, looks with the eye of a frightened gazelle-incredulously-temptingly. Swinging it with a blow to a blow, taking a lunge and reflecting as the shine of slided comet, translating outrage into joy, the most closed resonant system—consciousness works. It is important not to miss any "punch” (knock/sound/word) that is thrown into your consciousness, so that the sound of the universe (and it is she who sends impulses of understanding) turns into improvisation of your own thinking—becoming a landing from "personal Idaho state", so that the "muscles" of consciousness pumping iron-training do not sleep like a big earthworm that digested fast food (alimentary, cultured), being content with very little and chafing to empty, in order to work, interpreting what is happening near and around you, and comprehend creatively. The cohesion of eidos is so great that thought literally gains weight-you not only get tired quickly in the process of any "thinking”, but you feel that literally the world with weights hangs in your pockets, throwing a couple of blocks with houses and household on your shoulders. And this is all a consequence of the cohesion and microcoupling of all perceptions that revolve in your mind, touching them democratically: with fluids, resonating with waves of meanings, retransmitting impulses of images, and swaddling with the resulting introjections as by current-already according to Maxwell. Let us leave the God of God, art-skillful, and consciousness—seesaw swing of meanings...
\end{abstract}

Keywords: consciousness, language, Qualia, quasars of introjection, swing of meaning, thought, metaphor, thinking

The whole search tactic of my scientific research begins with my resistance to the generally accepted one-It is resistance that launches the "travel" strategy to find and confirm that it is tantamount to "neutralize", that artifact/concept, which is not "breathing" under wraps of other people's interpretations today. With resistance, my mind turns on and works as long as the charge is enough (the internal forces of my body) - I have not learned to save energetically, but to spend and give-Yes! consciousness is our pocket "garden of diverging paths", which, like The Old Summer Palace (Yuanming Yuan), is one of the Beijing parks that came to me as a "garden of stones and lotuses", where "stones" are stable systems of understanding, not devoid of flexibility, and lotuses-transparent and sensitive perception systems that are benevolent to photons of light and are affected to the eidos's quarks, which revolve in the intangible structure of consciousness that we

\footnotetext{
*Acknowledgement: This is a fragment from my chapter "Paradoxes of Consciousness or the emptiness of infinity". Menshikova, E. (2019). A created prayer of consciousness. SPb.: Aletheia, p. 528 (in Russian).

Menshikova Elena Rudolfovna, candidate of Cultural Research, New Institute for Cultural Research, Moscow, Russia.
} 
recognize as real, but everything changes in it, changing directions four times a second, but due to this fact "running slaver" by Carroll, the whole unstable platform of consciousness, as a floating sepal of lotus, quite stable and ready for balancing-he turned on his modulations of confidence, it looks for the participation, participating in the general excitement.

\section{Pro and Contra of Language Weakness}

Just looking for answers to questions, reality manages to throw; this actuality has an imperfect terracotta army of parasites and losers, a man, who in an endless search for "how to shoe a flea" (do smth, which requires exceptional skill, inventiveness, and craftsmanship), suddenly catches eidos, born of Eos'foam, like a butterfly in a net, as one of the breaths of consciousness-and only the seeking consciousness is revealed the meaning and harmony of life, and in simple images and clear forms, expressed through the specifics of the subject, and not an abstract concept, not sleeping in the kennel of the body, not running along the chain from pleasure to violence and backward. So, let us say, "slopes" in the direction of the physiological, as well as "squatting" around fir-tree, which in fact is not "our all”, but a glossy fetish, switch consciousness to another register, where the "understanding" itself, losing its quality and multidimensionality, prefers "color differentiation of pants" to the choir of the angels. We believe that research (study) is worthy only of consciousness, self-aware, studying proper "self-organizing chaos"-being-in-the-world, tormented by contradictions and seeking allegories and analogies to reflect/express this wonderful insane-crazy world. Only it knows for itself, from what chaos it is, thanks to some mudflow, fluid canzonas, and despite what chimeras it suddenly spills out with an insight to you, and even past you — so the passage of the cuckoo-by the visible outline of the perception of a particular object/phenomenon that alarmed you, pricked at discrepancy. In this "chimericality" of the process of awareness and thinking-from allusions and thin fibers of analogies, suddenly there is clarity and understanding of the problem, and the possibility of its solution as a harmonizing aspect of life. And the matter is not even in the complexity of the experiment-the study of consciousness, but of whether your sensors are capable of not twisting, plunging a tomograph into a stupor, when the "contacter"-the analyzed source of current of "consciousness"-is not withdrawn from its usual habitat, is not planted into a cone, not feed on Behavior's pills, is not torn out of the usual rhythm of life, habits, and activities, when non-verbal comprehension is actually performed, giving rise to an insight-the elf's breath-thoughts and understanding of the subject/issue, giving the gift a solution—by creating "something" that later will be in common thrift-box of artifacts of our civilization (without a hint of the canonization and apostolic embalming). In addition, here each growing branch is important: The problem of the correlation between the will of the mind (reason) and the will of the emanos-Who is who? It is important "how" the mind will cope with the raging emotional sphere, organizing, and rhythmicizing it, because the "arrhythmia of the mind" is harmful to consciousness by uneven jumps, because it seeks harmony of meaning, like a bloody lion who hunts water, or a running gazelle that loses moisture on grape eyes, which hope for divine order of correlations and proportions in the world-the radiant clarity of the meaning of being, rhythmically organized order, which allows you to get drunk and fill with light for everyone and how much everyone needs, including the lotus, silkworms, or a fallen leaf as a tear. However, if the brain, according to neurophysiologists (Medvedev V.), always works $100 \%$, it is reasonable to ask: Then why is consciousness so different, so frighteningly incompatible, so willful, and stubborn? You can answer with a joke (from the movie about Robin Hood) - “Because God loves diversity”. I think that the answer is a matter of the near future (unless, of course, our civilization suddenly collapses with a burned-out light bulb in 
the next twilight impasse), and is hidden behind the mirror screens of evolution and natural selection (if you recognize them not as an axiom, but at least for the very real position of things in the progress of the development of the organism/planet/society), in the very balancing of the system of the universe. It is like Picasso's famous "Girl on the Ball”-in every bend of a fragile body-the screaming atom of the imperfections of the world, and behind the quasi-gigantic of a gymnast looking indifferent like the idols of Easter Island-the solidity of material, which is the opulence of nature, balancing doubts, breaks, riots, revolution, and together these are roving radicals of being, that in its weightlessness they are engaged in self-organization of thought. You can call this the "introjection-design" of yourself and the world: I do not create "texts", but a single thought is added in a discrete way-a dotted line-this is how I interpret being and the person who is stuck in it as a rocket. Alas, it is not necessary to unravel the codes, checking the brain with bitcoin and cold information, that trash and lies, need not interrupt the consciousness to work: independently, by the sweat of one`s brow, performing this servagenicely.

The strategy of one scientific seminar, devoted to the problem of consciousness ${ }^{1}$, lurked in the minds of its organizers, and it was important for us-participants-to clarify (for everyone, I believe, according to his own intentions, maxims, and potencies): For what? What do you need? What for? Is surprise possible?-In a word, how far you have come to the edge, behind which consciousness hides and whether you are ready to jump after it into the abyss. If everything was started to produce (at the first onset-at the blink of an eye) another definition-then this is one more quest show in a series of others popularizing Itigelov's "mummy”. I dare to remind the Indian parable of one elephant and three wise men that turned up to be blind, but this did not prevent them to make their own judgment about the mammal that they felt receptor: By touching some of its parts, as if in a dismembered form (hello Sweeney Todd ${ }^{2}$ ), it was "true" for everyone, because it carried in itself a qualitative characteristic of a sensible object (elephant). Consciousness is elusive; you do not touch it by the tail, and so far, perhaps and fortunately, it does not fit on a shovel to put it in the oven by Ivashka (tomograph, which is a "Procrustean bed", as part of the "Artificial Intelligence” program, perhaps, counts on it). The witch Baba Yaga's horror stories: cyber raids, brain implants, tomographs "reading” thoughts (provided they live in the test head), a quantum "dismemberment" of the brain-operating on the subjunctive with ease of Ostap Bender: probably, possibly, will be done, presumably, by pushing the speculative experimental development (which is sitting on the state budget); they leave consciousness inoperative-not thinking, not comprehending the specifics of life, but absorbing an artificial test on a gluten basis, not illuminated by eidosor work-and these are all the steps in a dark room that will not bring to the good, because there is not even a smile of the Cheshire Cat. Contrary to the standing areal laughter coming from all the speakers of the mass culture, laughter's philosophy leaves consciousness, leaving it curved, deaf to both ears, and certainly dumb and gratuitously giggling and humorous, talkative, forgetting milestones of nature: thought to put on words.

What does drive crazy the emotional sphere, but does set in motion the mind? Language. In my opinion,

\footnotetext{
${ }^{1}$ Conducted at (Lomonosov) Moscow State University by K. Anokhin in 2017-2018.

2 The fictional character of the stories "The String of Pearls” by David Shannon and Thomas Peckett Prest, which were published in England (1846-1847), of urban legends themselves, horror stories about maniacs, in which the barber killed his visitors-it can be seen that in "good old England" there was some kind of soil favorable for the emergence of such a folk tradition-not fabulous (Baba Yaga, Viy, Vodyanoy, Leshy in Slavic or German mythology (fairy tales)), but its realistic form, where the murderer is a ripper of people (not chickens), certainly an artifact of urban culture and just like others among equals-just his hobby is his unpretentiously lucrative—so the "magic" of folklore was killed with sarcasm and the thought was instilled-through the "Overton window"-about the legitimacy of violence and the daily murder.
} 
impulse is driven by language. But language and thinking are not always identical, and languages, as a rule, are distinguishable-gesture, melody, voice, painting, sculpture, dance, smell, etc., and the fact that our emanos "twitches" pulls consciousness behind the hemline of "subconscious", as if to say, whispering and whistling, but, at the same time, conveying meaning, handing denotatum (meaning) with violet-art has long been using this "tools". In addition, every "word" is rich in inner content, which sometimes does not require verbalization, but, on the contrary, runs from it, noting "seagulls of bewilderment" ${ }^{3}$ that conceive their market bargaining as soon as there are many words, moreover, mass words, and tautology. On the other hand, the "seagulls of bewilderment" is that without which comprehension will roll up with a dried leaf and will ride with rattle as an empty cart past you. These Buridan's asses, screaming like tomcats (the March cats), awaken Qualia exactly - from your resistance and from your shudder giving rise to a tear of insight (that your gaping clam, barely having time to dig into the sand from an octopus-pirate), that suddenly "slows down" understanding, and perception can suddenly to be locked from the inside-inside the "Socratic dialogue" that leads the comprehending man's head (of course, references to the Head, with which Ruslan fought, are accepted, as well as to Professor Dowell's Head, and even to the order of the "Head" by young Gogol, but this is all metonymical reception (view of the trope)—transferring the general to the part), but whose consciousness is not trained, and for the sole reason that it resists to any equestrian vaulting. Microcommunications between language, emotions, and thinking—all this forms a "explosion beam" or the very "tracking resistance" that forms "at the blink of an eye", "at one gulp" the very glimpse of consciousness-this incredible act of "self-organization" of chaos, that higher energy, what is acting inside a person (without fixing a place) invisibly and like ether-that great component, the invisible element of the world (along with water, earth, fire, and metal) that creates the world, revealing the evolution of man (in all its divine diversity, including ironic aspect and Demiurge's trade), since it turns out to be a "galaxy in a spiral" on the neck of objective reality-of the Black Cat itself, which resists to description-after all, our life all the time eludes observation of me and the thoughtful eye of the universe, palming off the tail, the sublimation of hostility or touch and run with the "unconscious". Moreover, all these "long seeing off"-leads to the side—are created by consciousness itself in the mode of resonant swordplay and by the flow method: looking for analogies and tropes (associative series, allegories, and rhymes) in one pan-that boils by neurons of connections and consumes the lion's share of energy of the whole organism (almost 99\%), and weaves chains of comprehension by running-joining the processes-bundles. And this is the same "Prometheus's fire" that can descend with "holy fire", be "The burning bush", shade a "red flower" from any "Shere Khan", and even in the absence of a liver, experience the suffering of Titan (permanent torture of a pecking eagle as a metaphor instability and imperfection of the world), not looking for sympathy, but despite the fact that the arrows of empathy are directed in all directions - not everyone can catch them. Checking every star and every twisted ball, trusting them with our thoughts that we were not even born yet-but only ripen with sesame seed, only "sighs" and "ahi”, we are looking for something that answers us suddenly, but always very accurately, giving direction to reflections or eidos like a snowflake falling from the sky.

The language of science discourages intuitionists and creative creatures who work out for a "Socratic dialogue" with themselves or Being another language-those invisible mental passes that the Muses braided their pigtails hairstyles, and therefore a different "communicator" of interjections of perception and phonemes of meaning is needed, and I think, language of poetry could become such a regulator in the homing of a

\footnotetext{
${ }^{3}$ My allusion to the metaphor of Yu. Olesha from the novel "Envy": "seagulls hang with a question mark".
} 
cognitive bridge. Poetry is not only "riding into the unknown"; it is a kind of Koine Greek, or pidgin, which makes many go from prostration to thinking and, on the contrary, offers a good shake-up-a different register of deliverance of the frustrations that make the world percept dull, artificial, false, dooming the brain to doze with a routine sleep. Synoptic connections in the course of poetic excitation are enormous, if not flammable, everything works with breakneck speed, with Bengali sparks of words from one cup of allegory, when in poetic "throwing" consciousness searches for and finds the synapse that gives rhythm, meaning, and an image, and, extremely quickly - in a flash, improvising with the intuition and the stubbornness of the mind that it simply exercises in the paths of the tropes-as if hanging on the rafters of imagination, swaying on perceptions, and jumping over all the tackles of the mysterious caravel that floats in your depths his brain is his route, according to his fairway, without a navigator knowing how not to change his own course. In part, consciousness is the gene of resistance that drives evolution by the evolutionary method-empathic Qualia, the subjective perturbation of "natural selection", and the choice of which is not limited but stress-resistant to mistakes. In a word, correlation is possible by pressing your own key-the will, and the will of the mind, who himself knows what is right and what is not. It is like "anger management"-rhythmically, calmly, with the calmness of "a man in the prime of life", as if lifting a barbell, putting something in a corner—out of sight, nursing something and pouring warm water-in any case, pacify emanos are possible with creativity-the extreme occupation of rejected "others", like Banksy rushing at night to the coolness of an empty wall, to leave their own hieroglyph of their metalanguage as the voice-antithesis of the world, which is simply greedy and lazy, that loses beauty, that melts, running into its glacier a bacterium of violent deception-by escape in the canopy of the "Wailing Wall”, where tears, weaving roundelay of doubts, will find the solution of problems-mathematical, chess, political strategies-to anyone, even a hare-the main thing is that the process of the game is not only complicate, but "seeing" the problems of being, as if to "see through" our modernity—our involvement in this world, but also to understand the past time as the long-standing, which you always have in your pocket (in your clover, Orion's collar) to be able to read historical regularity, that is, to read, noting the errors, the evolutionary steps of civilization itself (in the totality of cultures and differences of perceptions). Looking into the mirror of ourselves, we bring evolution itself to the mirror, which, without blinking, looks with the eye of a frightened gazelle-incredulously-temptingly. Bekhtereva (2018) called such abilities of consciousness "Error Detection” and Platonov christened "the eunuch of the soul", accepting the fact that all our actions (and mental operations in the first place) pass the test in this incredulous box-cameraobscura of us. But "error detection", balancing between "unlawful" and "possible", "probable" and "outrageous", practicing the function of socialization, besides, it protects our body from "overheating" (especially the brain, and first of all, that it receives the distress signal "SOS” first ), thus guaranteeing delicate stability and survival, keeping from disease.

\section{Empathy as a Basis of Consciousness}

Swinging it with a blow to a blow, taking a lunge and reflecting as the shine of slided comet, translating outrage into joy, the most closed (of all on the planet and beyond) resonant system works. And the most significant are only two: consciousness and cosmos, and if one works in a "hidden" mode, then the other is open, but no less inaccessible by its "gaping emptiness", not only because of its mega-infinity, but boundless blurriness, looseness (spatial in the first), which makes the cosmos so far from understanding, ringing by the keys of knowledge, that they are, as if, in the public access, luring with the attraction of the "right of the first night” (jus primaenoctis)—the right of galactic pioneers, and mirroring in our minds with quasars of 
introjections of other people's perceptions that swing in a chaotic mode day and night. As if engaging in an invisible dialogue that lasts always and always invisible, for opponents eat ambrosia, inaccurate oxymorons sometimes produce a due: They catch the meaning (Pomerants, G. S.). There is a book Openness to the Abyss - we notice that the abyss is all open; at Zinoviev A. F.'s "Yawning Heights", we notice that "you can yawn" only with something excessive, which is below the angle of view-an abyss, for example. The pit, frightening by infinite emptiness, suddenly rises to the height of Mount Fuji, which is a symbol of absolute beauty and purity, overturns both the absolute and the height, all leveling with the "yawning void". Moreover, it is possible to "yawn" only in deathly silence-the grave beyond the limits. It is important not to miss any "punch" (knock/sound/word) that is thrown into your consciousness, so that the sound of the universe (and it is she who sends impulses of understanding) turns into improvisation of your own thinking — becoming a landing from "personal Idaho state", so that the "muscles" of consciousness pumping iron-training do not sleep like a big earthworm that digested fast food (alimentary and cultured), being content with very little and chafing to empty, in order to work, interpreting what is happening near and around you, and comprehend creatively. And if one in this deterministic world behind the looking-glass-universal ring-is enormously compressed (consciousness), then the other is separated immensely, stretched by pixels of stars and galaxies (cosmos). In these resonant systems, everything is verified: Every screw is in place; there are no resonators. Idle curiosity is in fact how one can characterize the process of studying cosmic something; there is the otherworldly view that it is outside, which is possible only from the "outside" system-the small circle (microdale), or the "big brother" zone, and need to mark, that it— "a view from the outside"-is not only possible (and not only due to the newest technologies), but it helps to "breathe" resonantly both the Colossus and the midget (little thing), and the microcosm of consciousness can also be immensely large, they seem to check the tension of the threads between yourself: is there a knot, that will interfere the intention of beauty-current silk of universe. And what is interesting, knowledge, and with it comprehension, as a result of reflection, it is only possible with such "idle curiosity"-only interest, including joy as an incentive for evolution, can move any stumbling block, turn a mountain, pave a tunnel, go through wall, leaving aqueduct for descendants. In Samos (Greece), the Tunnel of Eupalinos is an underground water supply system and, at the same time, a refuge of seven to eight meters deep and more than a kilometer in length $(1,036 \mathrm{~m})$, which constitute a two-shaft tunnel-through, with a gable roof of stone slabs landslides in the main mine-for the passage of people, built in the VI BC. Ancient Greek engineer and geometer Eupalinos from Megara (539-524 BC-in a short time by order of the Samoian tyrant Polycrates), using the principles of Euclidean geometry several centuries before they were formulated by Euclid himself (325-265 BC). That is, an aqueduct was built as a result of the "insight" of one consciousness-its calculations flew to it with still unsystematic qualia, foreseeing the scientific influx of the other.

The intuition of one artist, seeking to unravel the intent and intuition of another, helps to reveal the laws, and maybe the "divine intent" of what is happening - those "inconsistencies" of being that occur as a result of the imbalance of a separate consciousness - separated from others-by ambitions, underdevelopment, and "blindness deafness"-empathic isolation, what we call "insensitivity" — what King Lear had in abundance, by the will of his own "ego" lost the world around him (family and kingdom), and which Cassandra was deprived, but her "sensitive" gift frightened and alienated others by dictate of mocking gods: She was persecuted and feared, people despised her, because her empathic gift—naked perception, perturbing, woke up the wave strings of others-everyone beside her, who surrounded her, with systemic ones, which with the regularity of day 
changes anxiously vague gift was rejected, exposing the "donator" to ridicule. There are two extreme loneliness and two resonating reneged, a satirical dithyramb turning into an existential drama (Menshikova, 2018). And also two evidences of impossibility of love-love turns out to be that "redeeming sacrifice"-a "scapegoat" who is not sorry to be scorned, crucified, and defamed-she is a fetish and does not cost anything, because she is worth nothing. Developing the theme of the myth of troy, Shakespeare reduces the epic heroic to the routine of a military demarche, to the routine of war that endures vanity, lives cynicism, breathes dislike ("Troilus and Cressida"), and the beginning (prelude) of myth is the goddesses's dispute about beauty, that glares as the mirror of the tale of Pushkin, turns justice to Paris-the voluptuary is not important love, but only her "wafers"-simulacrum ("Lear"). So, the myth about war, which is conducted for the sake of love, transforms into a myth about the impossibility of love in general. The drama of the Vakhtangov Theater about the incredibility of love in the period of the Trojan battle lasting 10 years, which calls into question the very likelihood of war, where instead of scenery the only but correctly chosen attribute of the battle was a huge log, a meter and a half in diameter, hanging across the stage on massive chains, which in the course of the play were swinging, depicting a battering ram, sometimes mooed: usually-in the mornings, or zealously—on the eve of the battle. What is it? The roar of the Minoan-a fierce bull-man-the Minotaur, who must be mistaken for the symbol of an eternally at warring man, that he self-fulfills himself in a pirated way-war and robbery, simple domination? Or is it a cow that requires milking? It is funny and sad at the same time, but it becomes clear that the life of the Achaeans has settled-animal husbandry is established, bread is sown, battles are on schedule, from time to time, that is, after the works of the righteous, is revenge? Revenge by law? St. Petersburg's Lear, following the historical conventions of realism of the 16th century with the naturalistic costume, is shocked: If the remark says: In the suit of a beggar, the director is obedient to the playwright and Gloucester is simply naked. Scenography of L. Dodin and R. Tuminas, without moving away from Shakespeare's words, not for letter, creates, in fact, the newest "Brecht theater" about an endless war by Puritan minimalism of details, where the stiffness of metaphors knocks by the ashes of Mother Courage into every heart. The empathic gift of the filmmakers, creating and angering with the system of wave strings-mocking mirrors, makes the viewer turn on the error detector-re-think the phenomenon, the concept (love, war, and revenge) that has had time to dust under a pile of other people's interpretations, accustoming them to obedience and quiet asthenia.

Consciousness is turned on only by "gift"-free gift, violence is impossible, and if it is present, then somewhere near pathology is a modified format of contemplation and perception, when various incubuses take possession of consciousness, which collects no longer eidos, but sensual fears, working in a "chimerical" register: descending a host of all kinds of chimerical alkonosts that even stuck in the language practice-“nightmare consciousness" or "territare to consciousness", scaring and perturbing, internecine consciousness. "Caprichos" Goya flew out of this bag of Terror, that "long ago without a bottom”, and his physical indisposition (deafness as a result of the strongest migraines), aggravating the artist's already acute "vision" that he saw the "wrong side" of the world while still a court painter, it only intensified the horrors of the real life in Spain during the French wars, knocking on the drumming in his brain, with a restless scream of the crows broke the usual optics, and instead threw the grotesque-with curved lenses of the "nightmare". His stung heart screamed in pain and compassion, but, at the same time, overwhelmed the consciousness of others with lascivious laughter, while his "sorrowful consciousness", removing from the dense forest of stress-he beat the disease in others, inspired a painful experience in others-learned to empathize, learned to solve social problems, and learned to overcome adversity laughing, despite the "eternal discord"-the war. 
"Unconsciously"-what is it? One hundred years ago, a joke by a successfully practicing therapist turned out to be a cruel joke for those who were used to not bother themselves with superfluous thoughts, not to be embarrassed by syllogisms and scholi, whose mind was lazy, spinning "in idle”, was sick of boredom and apathy, because it did not work freely and giving, justifying, noticing only one mental operation-the one that leads to the achievement of benefits, that is, as a "conscious necessity", according to which instinct should be considered. All "other"-the Wingbird and the unconscious, including eidos, emanes, accomplishments, joy, and care-the whole range of existential modes, but note, with a positive charge-those cations of happiness that affect the physical balance of the whole human body and lead to the comprehension of harmony, it turns out to be unnecessary and harmful, and, therefore, as a "disease" to be cured, and this syllogism helped the doctor to successfully monetize his project-"psychoanalysis” was extremely popular in the 20th century. Let us give Freud Freudian, but the string harmony of the spirit is, I think, the true goal of human consciousness, and it is more valuable than complex complexes, no matter what turtles they are from, whatever stream they feed on. In painting and music, the same similar effect is hidden: traction (incomprehensible and touchingly daring) to convey space-like an imprinted perception of the moment-time or place, sometimes both together, but space like the terra nova of your stay/visit in it, and as a terra incognita of your discovery/intuition, and a capsule of your modus Vivendi, of your existence of the spirit. It cannot be conveyed to the "unconscious" only with a bare nerve of consciousness, always “conscious”.

The paradigm state of consciousness is still the same "Socratic dialogue”, but only with itself: honest, principled, but not "heart-to-heart", but "semantic load", seeking answers—with flashing eidos beacons—to uncomfortable questions, to problems: being, knowledge, faith, love, doubt and revelation-everything that requires "speaking", stripping to the back (even a single negative, even a double), adding all the costumes and understanding (Bekhtereva, 2018). Speaking of a stable/unstable altered state of consciousness, avoids the word "paradoxical", but refers to the definition of "static", which, by and large, is connected or tied to society, to generally accepted, standardizing norms and rules of behavior rather than standards "to think", but it should not be so in a world that is beautiful in its diversity—does Bechtereva's definition be not entirely true or incomplete? It gives a clinical definition (rather medical) for consciousness-an object that binds many, if not all, disciplines of knowledge, that is, requiring a common, accessible to many, and therefore dynamic "connecting element" and at the same time true (objectively perceived) applied to each type of knowledge, whether it is a humanitarian field, or natural science. You need to search for the consciousness of the right words! Not being afraid of the "winged" many, flying "out of nowhere" vocable, but straight under the shadow of your physicality.

Only then it will be possible to understand: "what is it?"-since objective understanding is born of hundreds of subjective understandings and perceptions, and what is interesting, art is able (and does very successfully) to convey other people's perceptions and feelings as their own, that existed thousands of years ago: Both Sophocles and Aeschylus with Euripides are understandable in many and surprisingly correlated with modernity, reflected in it inescapable actuality - “the imperfection of the world" —in different nations, people of different gender, age, genotype, and temperament. And the similarity of perception and experience discovered at the same time only testifies to a single "matrix" of consciousness, which was always, "distributed" to everyone a single "drop" with birth, and as a "procedure" accompanying the arrival of a new person into the world, it persists to this day-We receive our consciousness at birth, but how it will become-sharp-eyed or slanting-will depend on our training of the mind. The similarity of perception can lead us to the trail of the most mysterious phantom, which is not such, but it seems to many, consciousness, trying to resonate "contrary to", even being a "bounty hunter”, stick its 
head in the sand, sprinkle with ashes of reflections, leaving it with the head into empty speculations, alien "dark rooms" and walk bareheaded among the winds and sorrows that pour on our heads with tropical downpours. Cyclones rage and we continue to walk unconscious, as without an umbrella or a raincoat.

\section{Quasars of Introjection, or as Consciousness Swings}

The thought was defined by Sechenov as a "product" sensual, but, we add, gained as a result of "reflection". It has been noticed: All neurophysiologists are very optimistic—how wittily they manipulate brain quanta to weave the next subjuctive "epiphany" as their "Fermat's Last Theorem”! But why with such a massive outpouring of "feelings", to which mass culture working from solar batteries of pleasure dooms its consumers, accumulating and producing only it, that is, self-winding and life-giving system for the production of emotions: From pleasure to horror and fear, does the thought not arise everyone has? And if it suddenly appears, is there then some kind of torn scraps? Perhaps, there is not enough "push", which is impossible in the sensual environment? Let us answer with an example from "Chevengur": a paradox of holy fools, pretending to be fools. To Copenkin's question: Is the Soviet power possible in an open place-without buildings? They gave out wisdom, seeing the distance: "You can. If only there was poverty nearby and a white guard somewhere far away" (Platonov, 1988, p. 354). In a word, the "white guard" in the near undergrowth stimulates your consciousness to overcome difficulties and turn on the turbogenerator of ideas, which will allow you to organize and repel the enemy pressure, reorganizing, in the sense of rearranging on the move, or on modern slang - changing shoes in front of death entering in your house. Does such feeling of an inevitable eschatological outcome imply only "eschatological enthusiasm" "? Two denotation, "painful expectation of death" and "ecstatic excitement”, united by an oxymoronic swing, pushing away from each other, rolling and twisting, and again bouncing off contradictions, skillfully introducing the "sensual" into the "comprehended", lose the attributive sign, the dominant leaving the nominus-a noun with a cation of "unbridled joy" that does not imply any thinking at all. Conclusion: not a paradox lies behind every oxymoron—a judgment that sees the distance, that is, an objective truth. Inside the "swinging pair", we found "contact” and, adjoining with a communion, established communication between the modern rocker (Shnurov), the narrator of the Russian land (Platonov) and permanent social transformations with a single history of revolutionary "consumption" for all times and for every Terra that suddenly life begins to prefer Exodus.

The first popular science exposition of human neuropsychological activity was presented to the world by Democritus-the natural philosopher, whose positions formed the basis of Aristotle's teachings, and on Stagirit, the theory of knowledge, the system of scientific knowledge (categorical apparatus) and, in fact, Western philosophy (metaphysics, physics, politics, ethics, and poetics). The first atomist, Democritus, assigned to his emanos-feelings and emotions-the role of "organizers" and "builders" of all bodies and spaces in the universe, including space. And at the same time not a single fragment (as a written-fixed artifact) of its provisions reached us-only in the indirect transfer of students, adherents, historians of science, of whom there were many, and passing from mouth to mouth (by word of mouth) "insights" about the world, they tried to be precise in conveying the meaning of his judgments, keeping within themselves a certain point of their development, precisely that "communication" with the genius from Abder, who admired, amazed, and buzzed with his "vision" of the world and the depth of penetration into the essence of things, otherwise, the world

\footnotetext{
${ }^{4}$ This oxymoron was suggested by a St. Petersburg rock singer Shnurov.
} 
would not know about itself that "primordial values are infinite in number and indivisible in magnitude, that one cannot arise much or many one thing, but that everything is born by rallying and linking these first-bodies" (Lurie, 1970, p. 275), then there is an eternal spinning and invisible touch, and by the latter Democritus understood "(such arrangement when) the atoms are close to each other and are at a short distance" (Lurie, 1970, p. 260) - it is the free wind of empathy that only consciousness releases. We note, unlike other researchers, it enthralls us, and not the brain, who are the main self-regulator of the whole organism, the entire bodily organization. The cohesion of eidos is so great that thought literally gains weight-you not only get tired quickly in the process of any "thinking", but you feel that literally the world with weights hangs in your pockets, throwing a couple of blocks with houses and household on your shoulders. And this is all a consequence of the cohesion and microcoupling of all perceptions that revolve in your mind, touching them democratically: with fluids, resonating with waves of meanings, retransmitting impulses of images and swaddling with the resulting introjections as by current-already according to Maxwell. Note, we must always remember that our reasoning is speculative-we think, trying to isolate the mechanism of "work" of consciousness, without interrupting the course of all its gears, not breaking or closing windows and perception windows, which act as receptors of understanding, but also act—speculative-and all natural philosophers, including both Heraclitus and Leucippus. According to Democritus, the bodies that are "accessible to the senses", that is, sensory perception, which our consciousness possesses and uses,

collide with each other and are worn in the void as a result of dissimilarity and other...differences; being worn in this way, they collide and form such an interlacing that it forces them to touch each other and be close to each other, but nevertheless does not give rise to any one nature in the true sense. (Lurie, 1970, p. 275)

What is this, if not a description of the principle of the work of consciousness? Meaningful space, accommodating all bodies, bursts into your consciousness, or simply it has been there for a long time-everything is intertwined, touch invisible facets of images like kneecaps on a swing, but it is this intentional bending and touching of the knees that sets and the swing, and you and your feelings that not only make the heart beat faster, but also make the whole world spin around you with some kind of boisterous carousel, seeming as a rainbow world of hope. But sensual arousal can block/interrupt, if not completely, then partially, every thought that was moving in a free stream—sensuality hampers this flow, turning it into a duct that is threatened by drying out. However, the underdevelopment of feelings-the limited sensory perception (which is always "sensitive", like the policeman who loved the world and worried about everyone)—constrains the consciousness that the windows were not washed-its "receptors" are blind, broken, or ill pollen-less like a butterfly, that without it does not fly. This "pollen" is important to comprehending, giving an "interweaving" of images and meanings, giving birth to an understanding of something by touching the wings-touching the floating shadows on the wall of the cave, trembling the air in the nightingale's neck, swinging love, sharing, in a tangential, joy with man and the world. The problem is rather even in the other: How can consciousness not become unemployed? I think need to keep in the fairway of the Russian folk tale: Hut-hut, turn back to the forest, to me-in front! Since we still indulge in the old-time fun-entering the building bypassing the front door through the back door-our consciousness is in safe hands-we resist with laughter and circumstances and stupidity, but we move and breathe.

Everything in my head is born by a swing - a strike-click of the resonant system-in a blink of a quark (not even an eye!), and right there, with Prokofiev's overture, Ohm's resistance flounced-the currents of my 
consciousness test the idea and its plumage for strength, accuracy of sound, playfulness, on the consistency - that is, there is a ferment of the mind, when everything is questioned: Will it survive/swim out or will itself sink/dissolve? And initially there was an introjection in one gulp: The Plum Perfect of rapidly flying atomic meanings, which, touching upon past moments of life (everything happened in this money-box, but continues to move, is a fact fixed and continuing in the present perception, not only yours, but many others), the past is connected with the present, showing the effect of durability-so the collection of analogies and arguments, conducted by our consciousness, can be represented as simple arithmetic: II + AA = E (eidos), born of an echo of doubts, awakened by the Fire of Resistance, where II-introject impromptu, AA—allusions of associations (almost the Pythagorean theorem: the square of introjections plus the square of allusions). Such is the picture in oil about Prometheus, who is always mocking, a hero who has become a nominal character in our day, a kind of freak, like Diogenes, Thersites-loser, or Socrates, who was hiding from his wife in the agora, turning her into a list of thoughts. In the "simplified" world, all the heroes are impaired and simplified, but how else can it be-the outlaw (the human type that has rejected its roots lives in intercultural vacuum, leading a parasitic lifestyle, serving as a servant), only its own model-the low, lost sacredness and language, feelings (not to be confused with lust), consciousness, and therefore the renegade's sight is like "crooked mirrors"-the eyes of trolls, that they see not the inside out (of the world, people, phenomenon), but only flat and primitive, highlighting the "low" as a species advantage. If the reconnaissance of the other happens in a similar way-literally in an instant (yours that you direct and keep open, as if you are scanning the oncoming, which has not yet become "cross-sectional"), then the so-called "reading" of being and everything, that is in it and relate the beautiful, the terrible, the empty, the multidimensional, including their own kind and unmatched, despite the jumping illusions and the floating eidos that were embodied in the past by others in the images of the real and real, the spectral analysis of the rainbow mirrors of our consciousness and fast, but always quite right-in other words, we read in syllables, but surely we place emphasis with accurate intonation that gives the natural musicality, therefore, a developed ear-perception's receptors are normal. However, what about the artificial eye? Who will be in response to scan your associative rows? Artificial Intelligence will format Being. "Will you vouch for what it is made of?"-having slightly corrected, we parry the words of Professor Preobrazhensky. It seems that the artificial intelligence does not win in our touch and run, and therefore our "Kalabukhovsky house” will survive. This is not an assumption; it is an intuition of consciousness. Let us leave the god of God, art-skillful, and consciousness-seesaw swing of meanings. From the time of the archaic (idols as anthropomorphic fetishes), he began to make his own kind of people, and having learned to create plastic copies, he rushes to create his own clone (the homunculus groans in the corner), playing robots as before as soldiers, dissolving the mind in a virtual jelly—such a derogation of the perfection of human nature and its consciousness! Bad karma? Or not the inheritance, one should be proud of, every hour taking out of the dresser and stroking the bound collar as a great-grandmother. But "Man”, indeed, “sounds proud!”, however, with one "but": the natural right of upright walking and the breadth of judgment. II does not guarantee such "initiative"-it means you need to take care of your own eyepieces, clean the tear ducts, wash and fold and fold the squares of the cathetus, multiplying your own thought, releasing the feathered Sofia not only at night but also during the day-wising before the eyes (and in the eyes) of households and colleagues that your Vasilisa the Wisest. So, Eidos has to resonate: inject "breathe", becoming a unit multiplied by flying tangentially perceptions, pushing, forcing bending your knees, to soar over the being-in-the-world, to touch the senses, lean on the reflection (in the mirror of the sound image), not dissolving, but qualitatively changing due to flown 
analogies/allusions/introjections-as if growing by wings (associative series, identity, color mixing), writing the Chronicle of the Perfect Day, perfecting with the directed laughter, that it is a form of critical consciousness and to become meaningful voyeur of your reality, what happens once-from the moment of your birth, and lasts until the moment of your death. The brevity of life does not exclude its capacity (density), and how to fill it depends solely on you —on political reflection (if it exists) or habits (if it is not).

\section{Metaphor-Tao Meaning}

Emotions treat, darning our wounds, and destroy consciousness, forcing, condemning to samsara's "pitchfork", to attack the rake of offenses and defeats. My consciousness, "working” as a metaphor (operating as a fork knife), going as if to anticipate scientific hypotheses and actual problems (my modernity), is deliberately complicated: complicating the task of "producing" an idea/thought, I complicating the task of the so-called "potential contemplative"- to the one who only touches the feathering of my language of reflection. What to do? Do not you make yourself a "full circle" in the manner of Procrustes and at the call of Chepurny ${ }^{5}$ ? Is it necessary for Lear to tune up the crowds with tuning-fork, that now they is voiceless? Or indeed, it is pretty to the creator having tower or hut, but what if they turn out to be junk material? However, gold can turn into tiles, if you forget the right words; everything can turn into dust, even ivory towers, even you yourself, and at any minute. Therefore, only the "imperishable" turns out to be valuable, which is overgrown with invisible connections of other people's perceptions and associations. "My soul in the cherished lyre will survive my dust, since it will be alive in the sublunary world...” (Pushkin, A. S.). For us, he is the speaker, and for others? Is it a fallacy or his bluster? Illusions of consistency? Or would not that "straight walk", without which the "History of Pugachev's Rebellion" exist? Only the accomplishments of a person are worthy of respect-this is all the same Greek agon: to become better! And it takes a little for overtaking-to know yourself. As old as the hills, isn't it? But why not respected? Are they afraid that Prince Intellekt Ilyich will say? Or the one who will write his program? As far as the brain, aimed at finding an analogue (allusions to the exception), is adequate and does not fall into its own trap: Will be able to notice the differences, not seeing trouble in them, to sense "fear and awe” not as "the grapes of wrath"? The latter, by the way, is a qualitative advantage, which allows consciousness to look for connections, problems, and exits to world or chaos-in short, to find points and tussocks in the bifurcation boiler system, to find support where it is only supposed to, but not distinguishable. But the "difference" itself is built according to the scheme of "analogies": We only know what we had before witnessed, what we observed while contemplating or participating, what our eyes, ears, and hands were fascinated-the whole emotional veil, the entire receptive grid, all flagellum-antenna, observing a particular process, fact, phenomenon, chain of events, and the revealed "mystery" comes out stronger and brighter, when the impression is stunned and insolent, but it can also prevent the "objectivity" of the "imprinted" phenomenon that is seen-and therefore, another side- "estrangement" as a method of penetration in the essence of things, or the one who sits in the pond, who can smile at you, if you do it first, or the one who sees differently from you otherwise. We carry our "world behind the looking-glass" with us as a bunch of keys-each your "reflection" is your potential continuation, hypostasis, but also an incubus, and since behind any "Bluebeard" there is always a "Sinyushka's well”, "goggle-eyed" consciousness diligently (occasionally painfully, sometimes enthusiastically) peers. The "alien" eye can push on the "difference" that exists, and is not at all

\footnotetext{
5 The words of the hero "Chevengur" that sounded by the order of the tribunal, acting briskly and intimidating-execute, you cannot pardon!
} 
terrible, usual (for someone), habitual in its ordinary joy_like rainwater for an earthworm, like a rain-worm for a ouzel, like a singing ouzel for spring forest, like a forest filled with wind for walking lovers. Analogies help to "catch" the differences: to grasp the nuances, chequered light and shade and semitones-shades of introjections, which lead not only to an understanding of the clarity of the moment/subject/problem, but also to its true presentation (from the point of view of the subject-object, when objectivity is made up of many subjective opinions/views/sensations). Again, the question of responsibility arises as a "Wailing Wall"-practically anyone and everyone who has been drawn into the world of subject-object relations of the world of objectivities-everyone is responsible for the other, because you can be the other, being "own" and "alien" for the other. Moreover, this is not just an allusion to the "The Little Prince", it is pure Buddhism, when the world enters you completely, and when you cannot crush the silkworms (even by chance), because you can be (already) in his place-under a foot. And this is rather not "extraneous" (according to Camus), but "extraneous" to Diogenes: Everyone looks from his barrel, but not everyone is ready to get involved in relationships: to clash, touch, penetrate with care and participation, but seeks to reflect every touch (even invisible, like a blow of wings, like light breathing) with a blow, and usually sharp. “Alexander, you cover the sun for me!"- the philosopher's response to the emperor's greeting and the essence of the historical tale, which is a parable: Every fly speaks to God/Something directly, identifying itself with it. This is potentially at a minimum. The pride of everyone stumbles upon an analogue of his "divine wisdom", his "luminosity", and "many-watts", which causes an explosion of differences/contradictions, which leads to this foreign conflict-the elimination of the analogue as "difference" as Alien, Extra, and devoid of mind. How to deal with the fact that the foundation of many scientific theories is artistic works? For example, Plato's "The Republic" (the theory of a "perfect state") or Sophocles’s “Oedipus Rex" (the theory of "psychoanalysis”) ${ }^{6}$. The philosophical treatise "The Republic", composed for several years, filled with poetic expressions and lyrical digressions, is written in the form of a “dialogue”, like a dramatic work-waiting for its scenography scenes; the story of Oedipus in Greek mythology is one of the myths of the Theban Cycle, and the plot itself goes back to the matrilocal marriage, when a son cannot know his father, because he is brought up in the kind of mother, when reaching maturity goes in search of his father, and was not find out, and join in a battle with him. ${ }^{7}$ Therefore, the literary tradition rules the world and consciousness. How long? Where will we do tucks, gentlemen? Consciousness is silent and shells sunflower seeds...

There are no many questions: How does consciousness work? How? We put in the production exhibitor: gift and insight. Examining the debris of the "consciousness" pantry, right now, 20 years after the beginning of reflection on the ideas about the "grotesque consciousness", I was able (working ordinary: scribbling a new jacket to conference) to answer the question, which I had once during my speech of my first conferences: What is the difference between "carnivalized consciousness" and "grotesque consciousness"? Now I answer (as always with an insight): in the suffix and not only. "Carnivalized" is due to the framework (descent into the

\footnotetext{
${ }^{6}$ Wed: “All European philosophy is a series of notes to Plato” [Whitehead A.N. Process and Reality. N.Y., 1960, p. 13. Quote: Egunov A. N. "Plato: philosophy of state, law, politicians” (Foreword); Plato. "Republic-Laws-Statesman”. Moscow: MYSL, 1998, p. 5], Heidegger was of the same opinion.

7 Mythology: Illustrated Encyclopedic Dictionary. S-Pb.: Leningrad Gallery Foundation, 1996, p. 790. The essence of the myth is in the posthumous "recognition" of the father, and everything else (marrying his own mother, etc.) is a further elaboration of the mythological story about the son who killed his father, who was successfully engaged in the Athenian playwright Sophocles (496-406 BC), writing several tragedies (extant “Oedipus Rex" and “Oedipus at Colonus”), one of which (as a source) and attracted Freud for his psychological manipulations, completely changing the cause-and-effect motives in the personal drama of the married couple Oedipus-Jocasta.
} 
anti-world, if you wish), that is, it is chronotopically defined and focused on the Carnival-the course of action, time, place, and characters (masks). In the "grotesque consciousness" reflects the "political reflection" of man, his existential modus Vivendi, which is beyond time and space, this consciousness, overturning its "systematic approach" to life on the very being with laughter and tears, joking and sobbing at the same time. And as an aperitif I put forward a "national idea": Since in order to preserve the nation, it must preserve the "nation" and not the "elite" (which is highly doubtful as the "sturgeon of the second freshness"), then everyone should have "political reflection", for this purpose, to introduce the subject of "Political Reflection" into the Program of Primary School Education, along with "Calligraphy”, “Arithmetic”, and "Native Word”. Why not? Being able to control themselves, knowing the measure of all things, penetrating by their meanings, schoolchildren can easily read the hieroglyphs of unreasonable and unstable being. In order to realize something (notice) that your state is "not that", that is, changed, alien—jumping like avatar, not good-half-drunk, not much more stupid than where, similarly, ordinary, not yours-you need a dialogue with yourself, full of light and prudence. Without "political reflection" it may not be at all. I note that yoga classes will generally be taken far into the distance, because meditations and exercises aimed at achieving sensual pleasure imply a "stopping" of Consciousness—a practical "way out"-but not into space, but from the power supply system: "Blackout" is a pure uncluttered blockage and escape, actually castration of reason.

Unconscious, the head, not seeing any goal beyond its nose, is strategically deenergized, and therefore, is capable of pressing any button, can miss its own death-the bastions of civilization: education, art, science being under the oppression of primitive and superstition, already collapse like card houses. Even the conditions for this task have changed, like cyclones hopping around the planet, have been thrown off the old settings: The "goods" of civilization, which were invented as assistants, freeing man from work as a conscious need, destroy man, leaving helpless, knowledge, not giving the understanding, because consciousness is not accustomed to independent work, is useless and makes it difficult to find the right solution, as well as to formulate the right question, because they rotate in the brain's orbit like space debris, and this is created slagging (and that, by man himself) starts the process of metastasis—and the body devours itself. To make sure of this, it is enough to look around, read the press, look into the bookshop, go to school for a child or have a snack in a cafe, visit Agora. The "utter darkness" of our civilization consists in the fact that it has lost all its borders, erased tags, discarding keys - there is only one "soap bubble" — an inflated void, ready to burst at any second, which has lost its meaning as the basis of life, which loses sight, hearing, speech—those abilities of perception and understanding, that three thousand years ago, the Achaean tribes deduced from gloom out of the trouble of ecological disaster.

Metaphor, I repeat, is the shortest path to meaning. So, contrary to tradition, but paving the way for the new, I give my definition of consciousness closer to the finale:

Consciousness is self-organizing Chaos, which acts as a resonant system in the structure of dissipative Being, creating eidoses of perception and hiding quantums of meaning in art, producing enzyme of resistance to being-in-the-world, and therefore, it is also the art of resistance. 


\section{References}

Bekhtereva, N. P. (2018). The magic of the brain and the maze of life. M.: Publishing House AST.

Lurie, S. Y. (1970). Democritus: Texts-translation-research. Leningrad: Nauka Publishing House.

Menshikova, E. (2018). Myth as a redemptive sacrifice, or the silence of the lambs of Shakespeare's tragedy (16th century dramatic camera obscura on the stage of the 21st century). The XXVII International Scientific Conference, September 24-27, Moscow, Russia.

Platonov, A. P. (1988). The sea of youth: A tale, a novel. M.: Sovremennik. 